\title{
Corrosion Inhibition of Mild Steel Using Parinari polyandra Leave Extracts in Diluted Hydrochloric Acids
}

\author{
F. O. Nwosu ${ }^{*}$ and S. O. Amusat \\ Department of Industrial Chemistry, Faculty of Physical Sciences, \\ University of Ilorin, Ilorin, Nigeria \\ *Corresponding author: f.o.nwosu@gmail.com and fonwosu@unilorin.edu.ng \\ Received 02/03/2019; accepted 30/04/2021 \\ https://doi.org/10.4152/pea.2021390605
}

\begin{abstract}
Metallic materials remain an indispensable element in industries. The present study is aimed at the assessment of Parinari polyandra leaves inhibition properties on mild steel in a $1 \mathrm{M} \mathrm{HCl}$ solution. This was investigated using gravimetric and electrochemical methods. Physicochemical and spectroscopic analyses of the leaves extract were done using standard methods. A yield of $19.82 \%$ was obtained, while the leaves extract FTIR spectra showed bands of $3404 \mathrm{~cm}^{-1}$ and $2926 \mathrm{~cm}^{-1}$, which indicated the presence of a strong band of phenolic $\mathrm{O}-\mathrm{H}$ and $\mathrm{C}-\mathrm{H}$ stretch functional groups, respectively. A maximum corrosion inhibition efficiency of $97.22 \%$ was obtained. Langmuir adsorption isotherm fitted the inhibitor data well. From electrochemical methods, the corrosion rate value of 17.626 mmpy obtained for the uninhibited mild steel was higher than $0.02044-$ 2.2267 mmpy range values recorded for the mild steel surface covered with $P$. polyandra leaves extract in an acidic medium. SEM images showed the leaves extract inhibition effect against mild steel corrosion in a $1 \mathrm{M} \mathrm{HCl}$ solution. Electrochemical analysis using the Tafel plot also showed the leaves extract corrosion inhibition capacity, suggesting a mixed type inhibitor. Thus, $P$. polyandra leaves extract might act as a green corrosion inhibitor for mild steel utilized in industrial applications.
\end{abstract}

Keywords: Corrosion, Parinary polyandra, weight loss studies, adsorption isotherm, FTIR, SEM, thermodynamics and Tafel plot.

\section{Introduction}

The corrosion process is a naturally occurring phenomenon which daily affects our society and results into damage, destruction and degradation of household gadgets, automobiles, airplanes, highway bridges, military armored and petrol tanks, among others. High-impurity products can be originated during the crude oil extraction, which might enhance corrosion. In the case of oil and gas wells and pipelines, corrosive products, such as carbon dioxide $\left(\mathrm{CO}_{2}\right)$, hydrogen sulfide $\left(\mathrm{H}_{2} \mathrm{~S}\right)$ and free water can cause corrosion to them [1]. $\mathrm{CO}_{2}, \mathrm{H}_{2} \mathrm{~S}$ and free water continual extraction from oil and gas components can damage the inner surface of oil and gas wells and pipelines. This material degradation results in the loss of mechanical 
properties, such as strength, ductility, impact strength, and so on, which leads to materials damage, reduction in thickness and, at times, ultimate failure. If the degradation continues, the component may completely break down and require replacement. The serious consequences of the corrosion process became a problem worldwide [2].

Successful developments of researches to obtain natural corrosion inhibitors are growing simultaneously, as the demand for environmental protection has become higher [3]. Many noticeable research works have been published with the aim of developing non-hazardous corrosion inhibitors referred to as "green" corrosion inhibitors $[4,5]$. Also, there has been an increasing research on green plants, such as plants extracts, essential oils and purified compounds, to obtain non-toxic and cheap corrosion inhibitors [6]. El-Etre [7] investigated Baphia nitida leaves extract as a good mild steel corrosion inhibitor in $1 \mathrm{M} \mathrm{H}_{2} \mathrm{SO}_{4}$, while Nnanna et al. [8] reported the effect of Euphorbia hirta and Dialum guineense leaves extracts on aluminium corrosion in $0.25 \mathrm{M} \mathrm{NaOH}$. It has been shown that there is an inhibition effect of the Daucus carota aerial part extract on mild steel corrosion in a $1 \mathrm{M}$ hydrochloric acidic solution [9].

The possible application of Pentaclethra macrophylla Bentham leaves extracts as a corrosion inhibitor, as well as the inhibition effect of the natural onions juice extract of khillah (Ammi visnaga) on zinc corrosion, have been investigated [10, 11]. The Punica granatum extract corrosion inhibition efficiency, on brass in an acidic media, and that of fennel Foeniculum vulgare essential oil, on carbon, have been investigated $[12,13]$. The corrosion inhibition efficiency of green inhibitors on aluminium and alloys has been studied [14]. The corrosion inhibition properties of Raphia hookeri gum-halide mixtures on mild steel in an alkaline medium, using polyvinyl alcohol, have been studied [15].

However, there has been little study on the $P$. polyandra corrosion inhibition effect, with the exception of its leaves extract, on mild steel in a sulphuric acid solution, which is not detailed [16]. Therefore, this work emphasized the detailed investigation of $P$. polyandra leaves extract corrosion inhibition effect onto a mild steel surface in an acidic medium, using weight loss and electrochemical techniques, as well as kinectics, thermodynamics and adsorption isotherms studies.

\section{Experimental}

\section{Corrosive solution and mild steel specimens preparation}

The corrosive solution used in this study was a $1 \mathrm{M} \mathrm{HCl}$ solution prepared by measuring $86.0 \mathrm{~mL}$ (97\% purity of analytical grade) of the concentrated acid into a $1000 \mathrm{~mL}$ standard flask, and made up to the mark with the deionized water.

Mild steel sheets were purchased from Iron Sheet merchant, at Tanke Oke - Odo, Ilorin Kwara State, Nigeria. They were found to have the following composition (wt \%): Fe (98.89\%), Ti (0.73\%), Mn (0.20\%), Al (0.15\%), P (0.011\%), Mo $(0.006 \%), \mathrm{W}(0.0047 \%)$ and $\mathrm{V}(0.0024 \%)$, and they were cut into the same size $(2.5 \times 2.0 \times 0.85 \mathrm{~cm})$. The mild steel sheets were mechanically polished in separate, with Sic emery papers of grades 200, 400 and 600, in successive 
sections, washed with deionized water, degreased with ethanol, dried in acetone and kept in moisture free desiccators, prior to each carried out experiment [17].

Collected and extracted $P$. polyandra leaves, commonly known as abeere in yoruba, were obtained from the University of Ilorin, Ilorin, Nigeria, at a latitude of $8.4807^{\circ} \mathrm{N}$ and a longitude of $4.527^{\circ} \mathrm{E}$. The leaves were identified at the Herbarium in the Department of Plant Biology, University of Ilorin, Nigeria. $70.0 \mathrm{~g}$ of $P$. polyandra leaves were washed, dried, grounded and soaked in a $500 \mathrm{~mL}$ solution of ethanol (97\% purity), for $48 \mathrm{~h}$. After $48 \mathrm{~h}$, the samples were filtered, and the obtained filtrates were further subjected to evaporation at $352 \mathrm{~K}$, in order to make them free of ethanol. The extract stock solutions were used to prepare different extract concentrations, by dissolving $0.1,0.2,0.3,0.4$ and $0.5 \mathrm{~g}$ of it in $1 \mathrm{~L}$ of $1 \mathrm{M}$ $\mathrm{HCl}$, for gravimetric and electrochemical analyses [18]. The leaves extraction percentage yield was calculated by using the formula [19]:

$$
\% \text { yield of extraction }=\frac{M_{1}-M_{2}}{M_{1}} \times 100
$$

where $M_{1}$ is the sample and the thimble mass before extraction and $M_{2}$ is the sample and the thimble mass after extraction.

P. polyandra leaves extracts physicochemical and spectroscopic properties determination

Physicochemical parameters, such as yield $(\%), \mathrm{pH}$, conductivity $(\mu \mathrm{S} / \mathrm{cm})$, ash content $(\%)$, moisture content $(\%)$ and bulk density $(\mathrm{g} / \mathrm{mL})$, were determined using standard methods [5]. The $P$. polyandra leaves extracts Fourier Transform spectroscopic analysis was also done.

\section{Scanning Electron Microscopy (SEM) studies}

Two cleaned mild steel specimens were immersed separately in $50 \mathrm{~mL}$ of the blank (uninhibited $1 \mathrm{M} \mathrm{HCl}$ ) and inhibited $1 \mathrm{M} \mathrm{HCl}$ solutions, with $0.2 \mathrm{~g} / \mathrm{L}$ of the extract, for 48 hours, at room temperature $(303 \mathrm{~K})$, after which they were removed and dried in air. The dried mild steel sheets were then subjected to scanning electron microscopy (SEM), using a high vacuum Based SEM SCOTECH 30000 SEM (Germany), for obtaining the visual physical surface morphology of the uninhibited sheets and of those inhibited with $P$. polyandra leaves extract [10].

Corrosion inhibition effects measurement using weight loss studies

Each pre-weighed mild steel sheet was separately immersed in $50 \mathrm{~mL}$ of $1 \mathrm{M} \mathrm{HCl}$ without inhibitor (blank solution) and with different inhibitor leaves extract concentrations $(0.1,0.2,0.3,0.4$, and $0.5 \mathrm{~g} / \mathrm{L})$. The beakers were placed in a thermostated water bath [5]. The experiments were conducted at various temperatures of $303,313,323,333$ and $343 \mathrm{~K}$, for $10 \mathrm{~h}$ each.

Corrosion rate $(\mathrm{CR})$ and percentage corrosion inhibition efficiency were calculated using the equations 2 and 3 :

$$
C R\left(\mathrm{gcm}^{-2} h^{-1}\right)=\frac{w}{A t}
$$




$$
I E \%=\left(\frac{w_{1}-w_{2}}{w_{1}}\right) \times 100
$$

where $\mathrm{w}, \mathrm{A}$ and $\mathrm{t}$ are weight loss $(\mathrm{mg})$, exposed area $\left(\mathrm{cm}^{2}\right)$ and minimum time $(\mathrm{h})$, respectively, while $\mathrm{w}_{1}$ and $\mathrm{w}_{2}$ indicate the mild steel original weight and weight loss in either an uninhibited solution (blank) or an inhibited solution with the $P$. polyandra leaves extract.

Corrosion effects measurement using electrochemical studies

The electrochemical studies were performed using a VERSASTAT 400 complete de voltammetry and corrosion system model with V3 Studio software. The mild steel was cut into a $1 \mathrm{~cm}^{2}$ square area which was exposed to the corrosive media, with and without inhibitors, as working electrode, and an $\mathrm{Ag} / \mathrm{AgCl}$ rod as counter electrode. A saturated calomel electrode (SCE) was used as reference electrode, and it was connected by a Luggin's capillary. The experiments were undertaken at room temperature $(303 \mathrm{~K})$. The working electrode was immersed in a test solution for $1 \mathrm{~h}$, until a stable open circuit potential was attained. The Tafel analysis study was set from a cathodic potential of $-250 \mathrm{mV}$ to an anodic potential of $+250 \mathrm{mV}$, with respect to the corrosion potential, at a sweep rate of $1 \mathrm{mV} / \mathrm{s}$. The linear Tafel segments of the anodic and cathodic curves were extrapolated to corrosion potential, to obtain the corrosion current densities ( $\left.i_{\text {corr }}\right)$. Each experiment was carried out three times to estimate the electrochemical parameters reproducibility and average values which are reported [20].

\section{Results and discussion}

The yield is regarded as the quantity of product formed per the quantity of starting materials. Table 1 shows that $P$. polyandra leaves extract yield was $19.82 \%$, and its $\mathrm{pH} 4.8$.

Table 1. P. Polyandra leaves (raw and extracts) physicochemical properties.

\begin{tabular}{lcc}
\hline Physicochemical properties & Raw leaves & Leaves extract \\
\hline Yield $(\%)$ & $*$ & 19.82 \\
$\mathrm{pH}$ & 5.3 & 4.8 \\
Conductivity $(\mu \mathrm{S} / \mathrm{cm})$ & 714.19 & 431.24 \\
Ash content $(\%)$ & 6.34 & 7.21 \\
Moisture content $(\%)$ & 14.53 & 2.45 \\
Bulk density $(\mathrm{g} / \mathrm{ml})$ & 0.32 & 0.41 \\
\hline
\end{tabular}

* not applicable; percentage error for each parameter is less than $5 \%$.

The $P$. polyandra leaves extract inorganic mineral content, which represents the ash percentage, was found to be $7.21 \%$, while its moisture content was $12.45 \%$. The obtained extract conductivity was $431.24 \mu \mathrm{S} / \mathrm{cm}$, and its bulk density was $0.41 \mathrm{~g} / \mathrm{mL}$. It could also be observed that the raw leaves $\mathrm{pH}$ is comparable to that of their corresponding extract, as both fell within an acidic region of 5.3 and 4.8 
$\mathrm{pH}$, respectively. All raw leaves various parameters values were found to be higher than those of their corresponding extracts, with the exception of the ash content and bulk density values that were found to be greater in the leaves extracts. The increase in the leaves extracts ash content might be due to the chemical reagents used during their treatment.

\section{FTIR analysis}

The $P$. polyandra leaves extracts micrograph of the FTIR analysis is shown in Fig. 1 , while the assignment of important bands of this inhibitor is presented in Table 2.

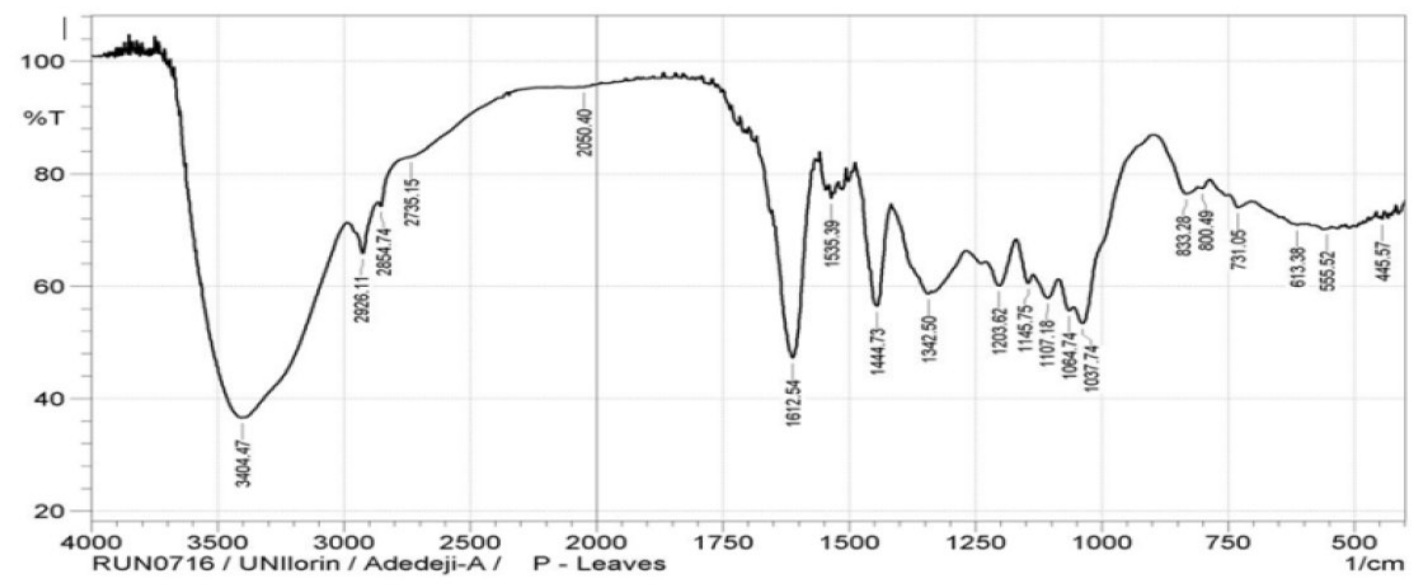

Figure 1. $P$. polyandra leaves extracts FTIR spectrum.

Table 2. Assignment of the important peaks observed in the $P$ polyandra leaves extracts.

\begin{tabular}{cc}
\hline $\begin{array}{c}\text { Absorption band location of P. polyandra leaves } \\
\left(\mathbf{( m}^{-1}\right)\end{array}$ & Types of vibration and assignments \\
\hline 3404 & OH stretching vibration of phenolic group \\
2926 & C-H stretching vibration of methoxyl group \\
1612 & C=C ring stretch (conjugated) in aromatic \\
1444 & O-H bend of carboxylic acids \\
1342 & C-C stretch in ketones \\
1203 & C-C $(\mathrm{O})-\mathrm{C}$ stretch of esters \\
\hline
\end{tabular}

A strong band at $3404 \mathrm{~cm}^{-1}$ was discovered and assigned to phenolic $\mathrm{OH}$ stretching vibration of the phenolic groups involved in the hydrogen bond. The bands at $2924 \mathrm{~cm}^{-1}$ were assigned to $\mathrm{C}-\mathrm{H}$ stretching vibrations of the methoxyl group in $P$. polyandra leaves extract.

At the band of $1444 \mathrm{~cm}^{-1}, \mathrm{OH}$ bend in carboxylic acid was observed in $P$. polyandra leaves extract, while the band at $1342 \mathrm{~cm}^{-1}$ revealed the $\mathrm{C}-\mathrm{C}$ stretch of ketones in the inhibitor. Bands at $1203 \mathrm{~cm}^{-1}$ and $1220 \mathrm{~cm}^{-1}$ were assigned to the $\mathrm{C}$ $\mathrm{C}(\mathrm{O})-\mathrm{C}$ stretching vibrations of esters in bonds in aliphatic ethers of $P$. polyandra leaves extracts. The absorption bands at $833 \mathrm{~cm}^{-1}-555 \mathrm{~cm}^{-1}$ indicate the heteroatoms presence in the inhibitor.

\section{Corrosion studies}

The corrosion studies involve the assessment of a given metal material loss extent, when it is exposed to certain harsh conditions. Although the gravimetric method 
is not very reliable, it is time consuming and cannot effectively predict the corrosion reaction mechanism, corrosion measurements can also be carried out using electrochemical techniques [19]. Table 3 indicates the various data obtained from the gravimetric method of mild steel weight loss calculations, in $1 \mathrm{M} \mathrm{HCl}$ of uninhibited and inhibited solutions, with different inhibitors concentrations, at various temperatures.

Table 3. Mild steel corrosion parameters in $1 \mathrm{M} \mathrm{HCl}$, with various leaves extract concentrations, at different temperatures, using weight loss technique.

\begin{tabular}{|c|c|c|c|c|c|}
\hline $\begin{array}{l}\text { LEC } \\
(\mathrm{g} / \mathrm{l})\end{array}$ & $\begin{array}{l}\text { W L } \\
\text { (g) }\end{array}$ & $\begin{array}{l}\text { Temperature } \\
\text { (K) }\end{array}$ & $\begin{array}{c}\text { C R R } \\
\left(\mathrm{gcm}^{-2} h^{-1}\right)\end{array}$ & $\boldsymbol{\Theta}$ & IE (\%) \\
\hline Uninhibited & 1.1011 & $303 \mathrm{~K}$ & 0.0404 & N.A & N.A \\
\hline 0.1 & 0.4875 & & 0.0195 & 0.09475 & 94.75 \\
\hline 0.2 & 0.2646 & & 0.0195 & 0.9722 & 97.22 \\
\hline 0.3 & 0.4653 & & 0.0186 & 0.9529 & 95.29 \\
\hline 0.4 & 0.5788 & & 0.0231 & 0.9404 & 94.06 \\
\hline 0.5 & 0.4553 & & 0.0182 & 0.9539 & 95.39 \\
\hline Uninhibited & 1.4399 & $313 \mathrm{~K}$ & 0.0575 & N.A & N.A \\
\hline 0.1 & 0.9562 & & 0.0382 & 0.8991 & 89.91 \\
\hline 0.2 & 0.8546 & & 0.0341 & 0.9192 & 91.92 \\
\hline 0.3 & 0.7825 & & 0.0313 & 0.9197 & 91.97 \\
\hline 0.4 & 0.6439 & & 0.0257 & 0.9317 & 93.17 \\
\hline 0.5 & 0.5112 & & 0.0204 & 0.9491 & 94.91 \\
\hline Uninhibited & 1.6502 & $323 \mathrm{~K}$ & 0.0600 & N. A & N. A \\
\hline 0.1 & 1.1232 & & 0.0449 & 0.8871 & 88.71 \\
\hline 0.2 & 1.0056 & & 0.0402 & 0.8929 & 89.29 \\
\hline 0.3 & 0.8481 & & 0.0339 & 0.9104 & 91.04 \\
\hline 0.4 & 0.7931 & & 0.0317 & 0.9230 & 92.30 \\
\hline 0.5 & 0.6215 & & 0.0248 & 0.9430 & 94.30 \\
\hline Uninhibited & 2.3215 & $333 \mathrm{~K}$ & 0.0986 & N. A & N. A \\
\hline 0.1 & 1.4312 & & 0.0502 & 0.8585 & 85.85 \\
\hline 0.2 & 1.2556 & & 0.0502 & 0.8871 & 88.71 \\
\hline 0.3 & 1.0563 & & 0.0422 & 0.8920 & 89.20 \\
\hline 0.4 & 0.9825 & & 0.0393 & 0.9059 & 90.59 \\
\hline 0.5 & 0.7784 & & 0.0311 & 0.9219 & 92.19 \\
\hline Uninhibited & 3.1358 & $343 \mathrm{~K}$ & 0.1254 & N. A & N.A \\
\hline 0.1 & 1.7842 & & 0.0713 & 0.8203 & 82.03 \\
\hline 0.2 & 1.6045 & & 0.0642 & 0.8339 & 83.39 \\
\hline 0.3 & 1.5213 & & 0.0608 & 0.8404 & 84.04 \\
\hline 0.4 & 1.3786 & & 0.0551 & 0.8514 & 85.14 \\
\hline 0.5 & 1.2015 & & 0.0480 & 0.8780 & 87.80 \\
\hline
\end{tabular}

LEC $=$ leaves extracts concentration, $\mathrm{WL}=$ weight loss, $\mathrm{CR}=$ corrosion rate, $\theta=$ degree of surface coverage, $\mathrm{IE}=$ inhibition efficiency, $\mathrm{NA}=$ not applicable.

The corrosion rate was found to decrease with higher inhibitor concentrations and temperatures. The temperature of $303 \mathrm{~K}$ and the increase in P. Polyandra leaves extract concentrations, from $0.1 \mathrm{~g} / \mathrm{L}$ to $0.5 \mathrm{~g} / \mathrm{L}$, caused the mild steel corrosion rate to decrease from 0.0195 to $0.0182 \mathrm{gcm}^{-2} \mathrm{~h}^{-1}$ (as seen in its plots of Fig. 2), in line with the results obtained in literature [20].

Akpan and Offiong [21] also reported a similar trend of the results, when ciprofloxacin drug was used as an eco-friendly inhibitor.

Also, the $P$. Polyandra leaves extracts inhibition efficiency (IE) ranged from 97.22 to $82.03 \%$ (Table 3). The EI increased gradually with higher inhibitor concentrations, but decreased with a rise in temperature. Maximum inhibition 
efficiency of $97.22 \%$ was obtained at $0.2 \mathrm{~g} / \mathrm{L}$ of $P$. Polyandra leaves extracts in a $1 \mathrm{M} \mathrm{HCl}$ solution, at a temperature of $303 \mathrm{~K}$.

A similar trend has been reported in literature [22], when red onion skin acetone extract was used as a corrosion inhibitor for zinc in a $2 \mathrm{M}$ hydrochloric acidic solution.

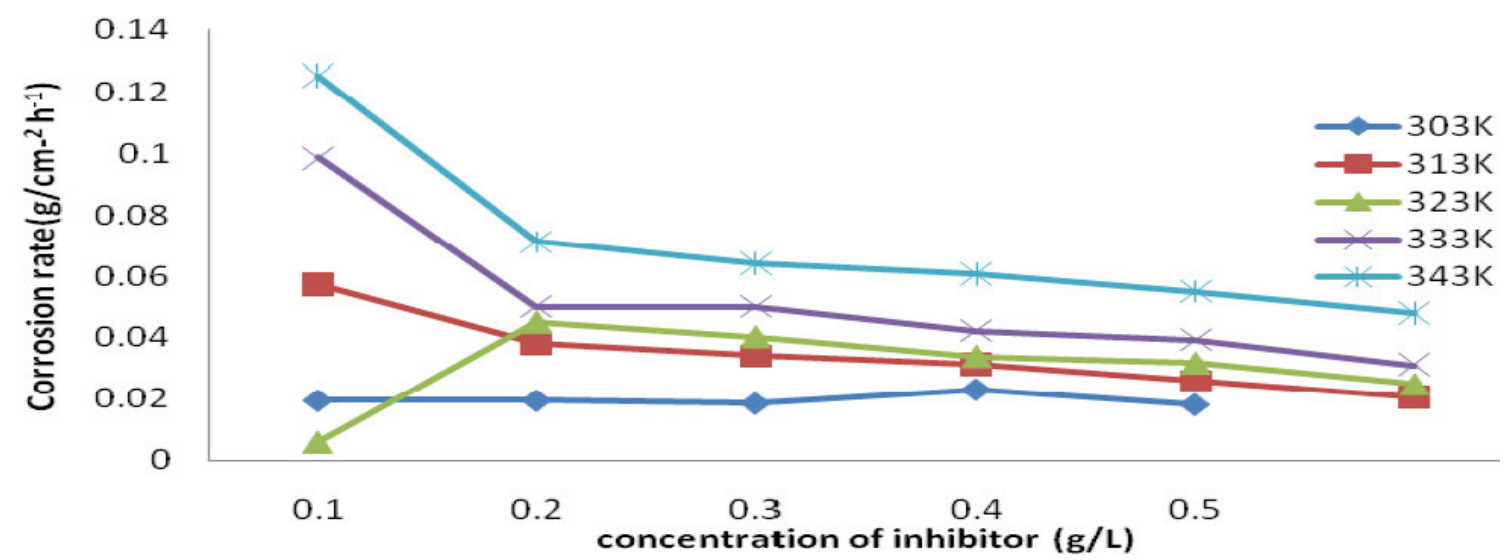

Figure 2. $P$. polyandra leaves extracts concentration effect on mild steel corrosion rate, in $1 \mathrm{M} \mathrm{HCl}$, at various temperatures $(303-343 \mathrm{~K})$.

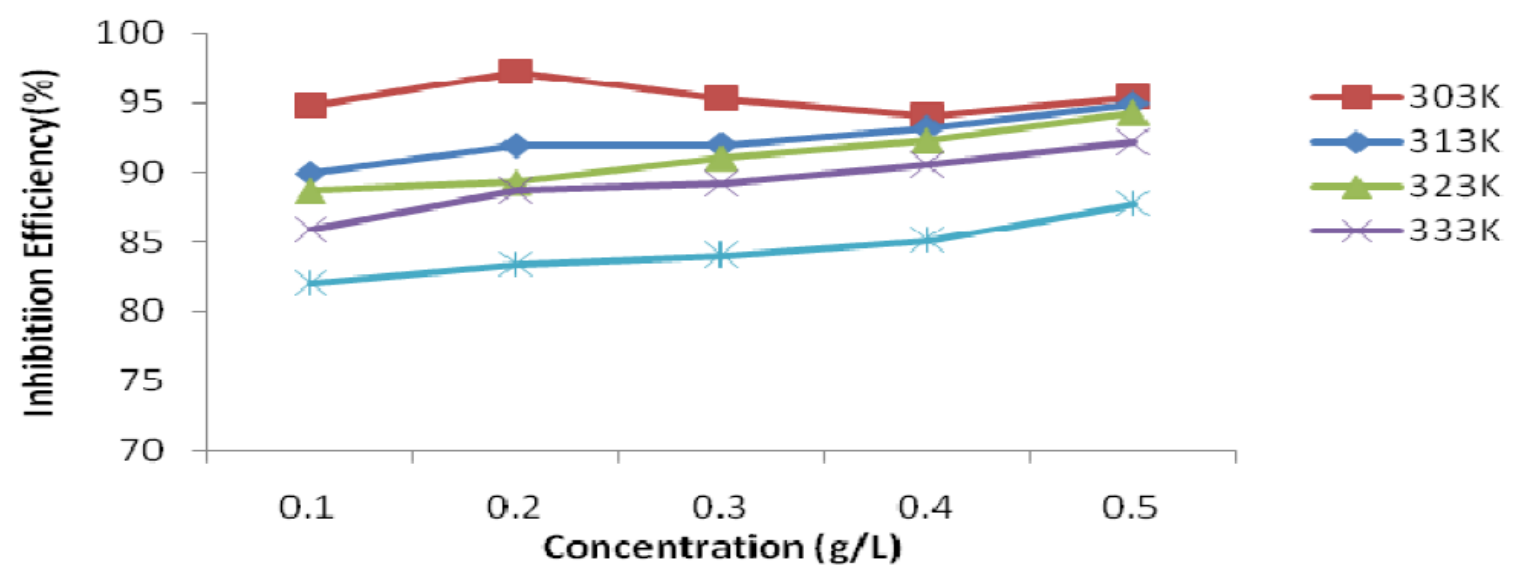

Figure 3. $P$. Polyandra leaves extract concentration effect on its inhibition efficiency on mild steel corrosion in $1 \mathrm{M} \mathrm{HCl}$, at a temperature range from 303 to $343 \mathrm{~K}$.

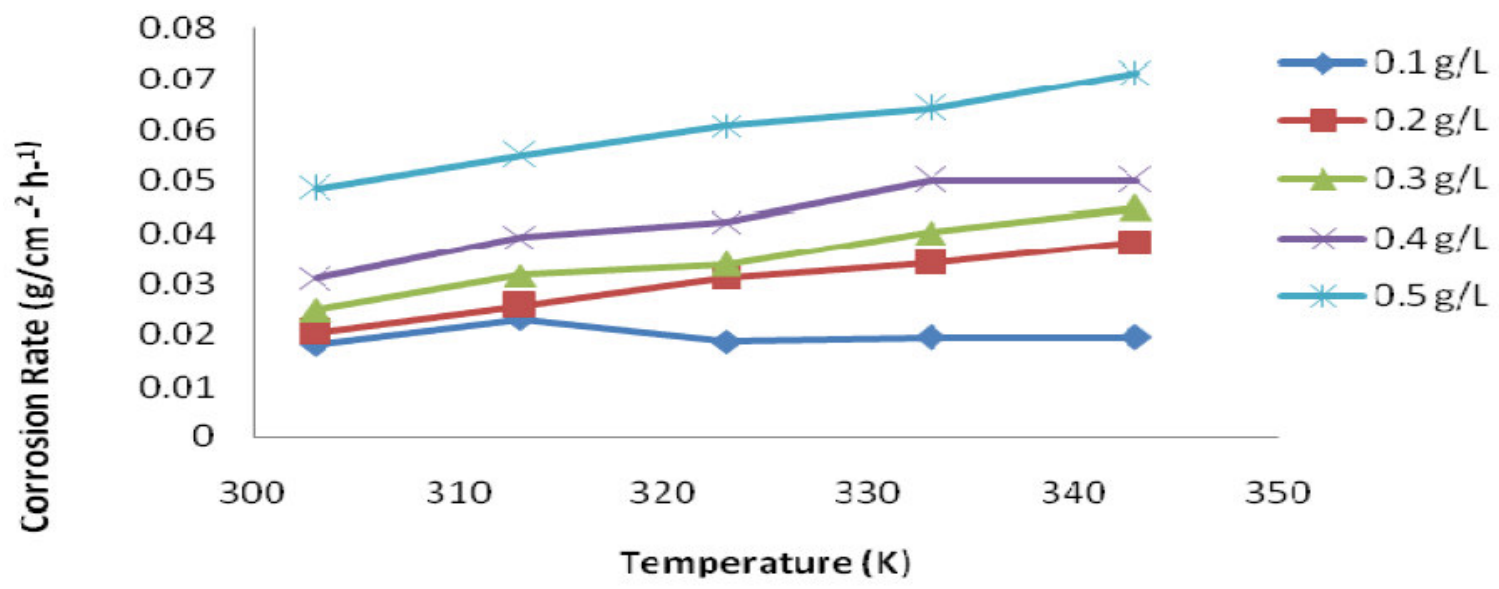

Figure 4. Temperature effect on mild steel corrosion rate in $1 \mathrm{M} \mathrm{HCl}$ inhibited with Parinari Polyandra leaves extract, at various temperatures $(303-343 \mathrm{~K})$. 
The IE variation with $P$. polyandra leaves extract concentrations at various temperatures, ranging from $303 \mathrm{~K}$ to $333 \mathrm{~K}$, is shown in Fig. 3. It can be observed that, as temperature increased, the $P$. polyandra leaves extract inhibition effect on the mild steel corrosion decreased, with the various investigated concentrations (Fig. 3). This is because the tendency of the leaves extract molecules to be attached to the mild steel surface decreases with higher temperatures [22].

Fig. 4 depicts the corrosion rate of mild steel inhibited with various $P$. polyandra leaves extract concentrations, at different temperatures.

\section{Immersion time effect}

The immersion time effect on mild steel corrosion rate (CR) and on inhibition efficiency (IE) in a $1 \mathrm{M} \mathrm{HCl}$ corrosive environment is shown in Table 4. The CR, in uninhibited and inhibited $\mathrm{HCl}$, and IE, in the presence of leaves extracts maximum concentration, at room temperature, were calculated using their respective formulae, at a 3 days interval, for a total of 18 days. Mild steel corrosion parameters, in $1 \mathrm{M} \mathrm{HCl}$, without inhibitor and with $0.5 \mathrm{~g} / \mathrm{L}$ of $P$. Polyandra leaves extracts, at different immersion times, at a temperature of $303 \mathrm{~K}$, using weight loss techniques, are presented in Table 4.

Table 4. Time of immersion effect on the mild steel corrosion rate in uninhibited and inhibited $1 \mathrm{M} \mathrm{HCl}$ solutions, with various $P$. polyandra leaves extract concentrations.

\begin{tabular}{|c|c|c|c|c|c|c|c|}
\hline $\begin{array}{l}\text { Inhibitor } \\
\text { type }\end{array}$ & $\begin{array}{l}\text { Immersion time } \\
\text { (days) }\end{array}$ & $\begin{array}{c}\text { W L } \\
\text { (g) } \\
\text { Uninhib }\end{array}$ & $\begin{array}{l}\text { W L } \\
\text { (g) } \\
\text { Inhib }\end{array}$ & $\begin{array}{c}\text { CR } \\
\left(\mathrm{g} / \mathrm{cm}^{2} \mathrm{~h}\right) \\
\text { Uninhib }\end{array}$ & $\begin{array}{l}\text { CR } \\
\text { (g/cm) } \\
\text { Inhib }\end{array}$ & $\boldsymbol{\theta}$ & IE (\%) \\
\hline \multirow[t]{6}{*}{ Leaves } & 3 & 0.132 & 0.103 & 0.052 & 0.020 & 0.9541 & 95.41 \\
\hline & 6 & 0.190 & 0.168 & 0.076 & 0.045 & 0.9022 & 90.22 \\
\hline & 9 & 0.256 & 0.205 & 0.145 & 0.057 & 0.8615 & 86.15 \\
\hline & 12 & 0.297 & 0.278 & 0.295 & 0.075 & 0.8392 & 83.92 \\
\hline & 15 & 0.300 & 0.295 & 0.304 & 0.109 & 0.8040 & 80.40 \\
\hline & 18 & 0.350 & 0.325 & 0.584 & 0.250 & 0.7521 & 75.21 \\
\hline
\end{tabular}

WL means weight loss, CR is the corrosion rate, $\theta$ represents surface coverage and IE is inhibition efficiency. Temperature is at $303 \mathrm{~K}$.

From Table 4, it is observed that MS corrosion rate in uninhibited $1 \mathrm{M} \mathrm{HCl}$ increased from $0.052 \mathrm{~g} . \mathrm{cm}^{-2} \mathrm{~h}^{-1}$, after 3 days of immersion, to $0.584 \mathrm{~g} . \mathrm{cm}^{-2} \mathrm{~h}^{-1}$, after 18 days of immersion.

This trend also occurred when a $1 \mathrm{M} \mathrm{HCl}$ solution was inhibited with the $P$. Polyandra leaves extract, as the corrosion rate went from $0.020 \mathrm{~g} . \mathrm{cm}^{-2} \mathrm{~h}^{-1}$, after 3 days of immersion time, to $0.250 \mathrm{~g} . \mathrm{cm}^{-2} \mathrm{~h}^{-1}$, after 18 days of immersion time.

Fig. 5 shows the immersion time effect on the corrosion rate of mild steel immersed either in an uninhibited $1 \mathrm{M} \mathrm{HCl}$ solution or in $1 \mathrm{M} \mathrm{HCl}$ inhibited with $0.5 \mathrm{~g} / \mathrm{L} P$. polyandra leaves extract; at this concentration, the metal corrosion rate was the lowest (Fig. 5). 


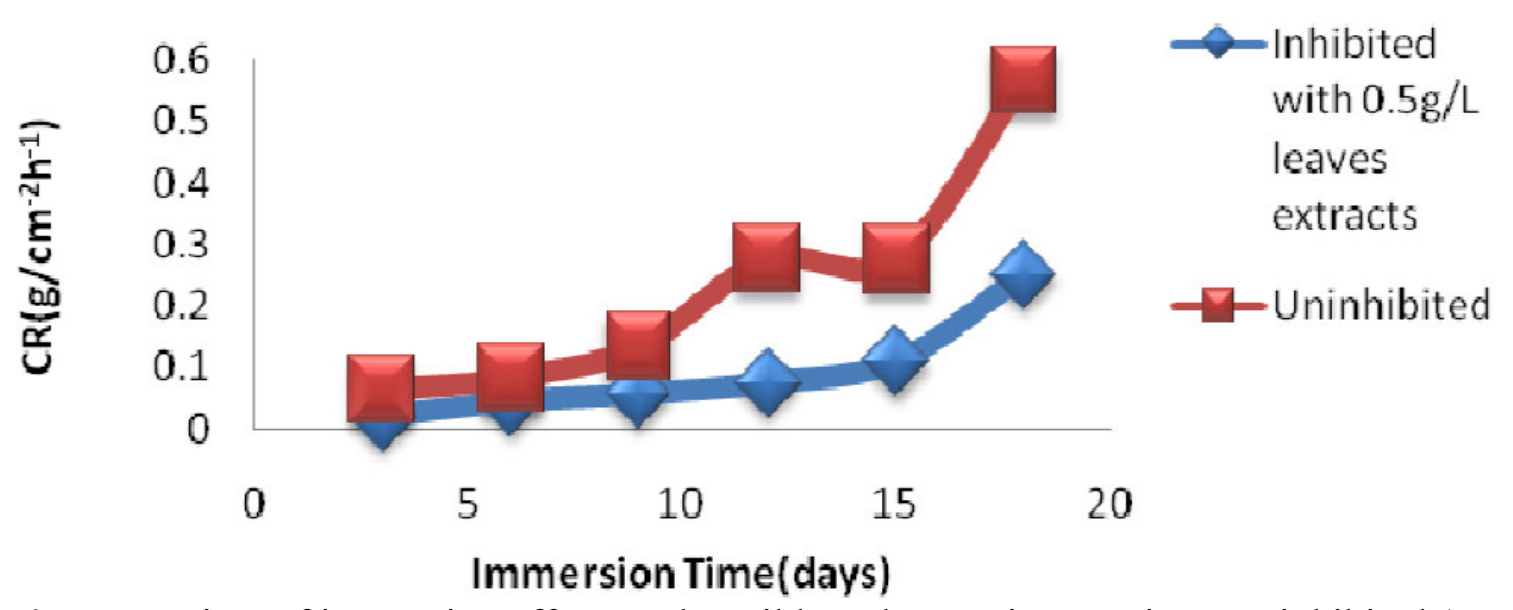

Figure 5. Time of immersion effect on the mild steel corrosion rate in an uninhibited $1 \mathrm{M}$ $\mathrm{HCl}$ solution and in $1 \mathrm{M} \mathrm{HCl}$ inhibited with the $0.5 \mathrm{~g} / \mathrm{L}$ leaves extracts solution.

\section{Adsorption studies}

Adsorption isotherms are very important in determining the mechanism of organoelectrochemical reaction. The corrosion inhibition of mild steel in a $1 \mathrm{M} \mathrm{HCl}$ medium with different $P$. polyandra leaves extract concentrations can be explained by the inhibitor components adsorption onto the metal surface. Inhibition efficiency (\%) is directly proportional to the surface fraction covered by the adsorbed molecule $(\theta)$. Therefore, the adsorption isotherm describes the relationship between the interface coverage with the adsorbed species and the latter concentration in the solution. The extract surface coverage $(\theta)$ value at different inhibitors concentrations in a $1 \mathrm{M} \mathrm{HCl}$ solution was made to fit various adsorption isotherms.

\section{Modified Langmuir adsorption isotherm for corrosion studies}

Using this modified Langmuir expression shown in equation 4 [23]:

$$
\frac{C_{i n h}}{\theta}=\frac{m}{K_{a d s}}+m C_{i n h}
$$

Langmuir plot of $\frac{C_{\text {inh }}}{\theta}$ against $\mathrm{C}_{\text {inh }}$ gave straight lines for the $1 \mathrm{M} \mathrm{HCl}$ solution inhibited with $P$. polyandra leaves extracts. Figs. 6 and 7 clearly show that the leaves extract adsorption onto the mild steel surface fitted very well the modified Langmuir equation, as the inhibitor correlation coefficients fell within the range from 0.998 to 0.999 , at the temperature range from 303 to $343 \mathrm{~K}$. Table 5 summarizes the obtained Langmuir parameters.

It is known that $\mathrm{K}_{\mathrm{Lads}}$ describes the inhibitor adsorption strength onto the mild steel surface [5]. The large $\mathrm{K}_{\text {Lads }}$ values suggest an efficient inhibitor binding with the mild steel surface [24]. In this study, the $\mathrm{K}_{\mathrm{L}}$ value could be seen to slightly increase as the leaves extracts temperature rose from 303 to $343 \mathrm{~K}$. The lowest $\mathrm{K}_{\mathrm{Lads}}$ value obtained for the leaves extracts, at $303 \mathrm{~K}$, was found to be $1.0499 \mathrm{~g} / \mathrm{L}$. 


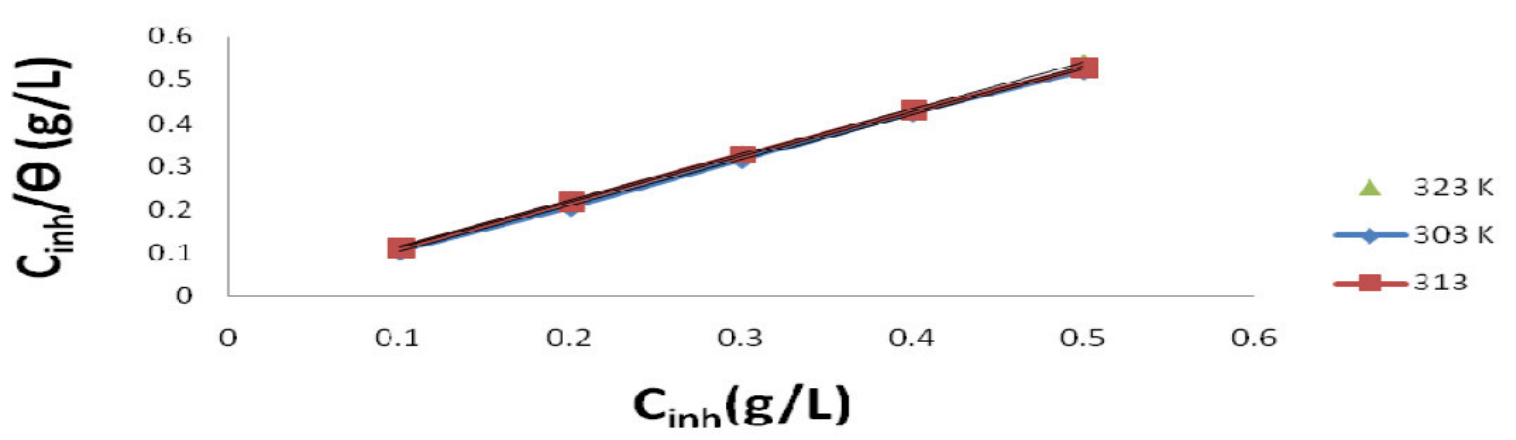

Figure 6. Langmuir plot for mild steel in a $1 \mathrm{M} \mathrm{HCl}$ solution inhibited with different $P$. Polyandra leaves extract concentrations, at various temperatures.

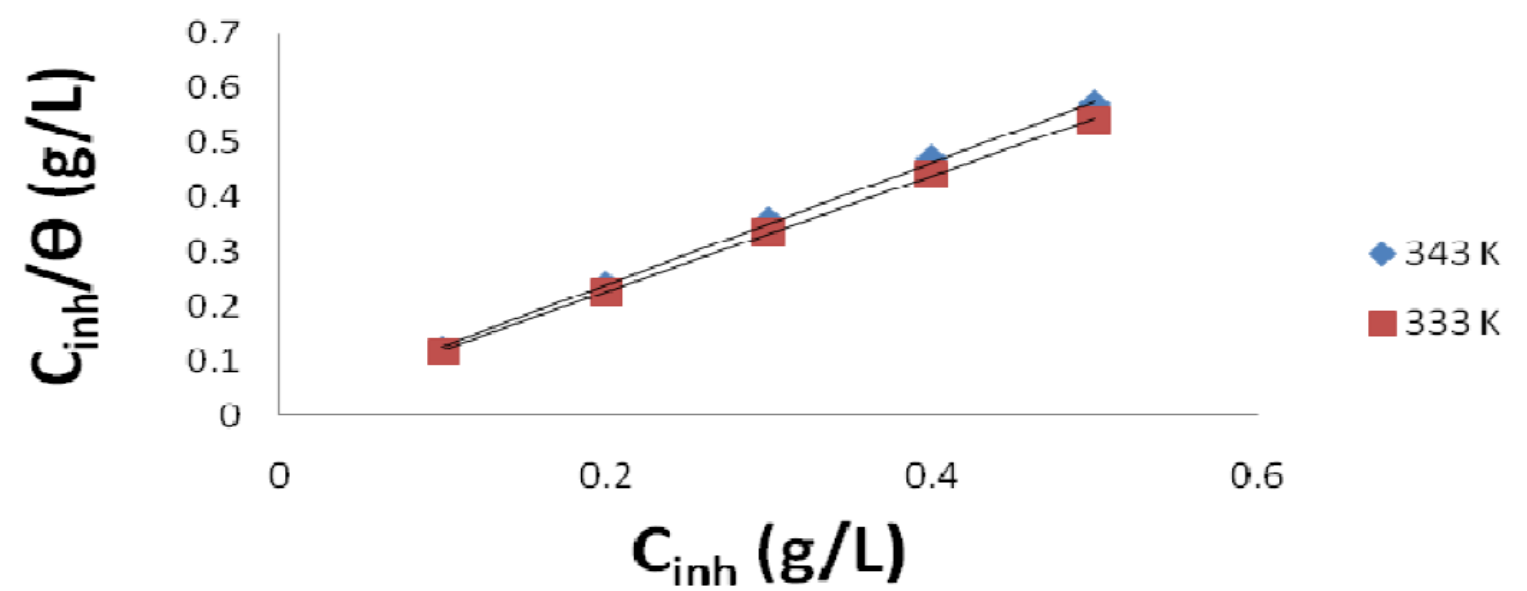

Figure 7. Langmuir plot for mild steel in a $1 \mathrm{M} \mathrm{HCl}$ solution inhibited with different $P$. Polyandra leaves extract concentrations, at two temperatures.

Table 5. Langmuir parameters for mild steel in a $1 \mathrm{M} \mathrm{HCl}$ solution inhibited with different $P$. polyandra leaves extract concentrations, at various temperatures.

\begin{tabular}{llll}
\hline $\begin{array}{l}\text { Temperature } \\
(\mathbf{K})\end{array}$ & $\begin{array}{l}\text { Leaves extract } \\
\mathbf{K}_{\text {Lads }} \\
(\mathbf{g} / \mathbf{L})\end{array}$ & $\mathbf{m}$ & $\mathbf{R}^{\mathbf{2}}$ \\
\hline 303 & 1.0499 & 1.051 & 0.999 \\
313 & 1.0509 & 1.043 & 0.999 \\
323 & 1.0669 & 1.059 & 0.999 \\
333 & 1.0779 & 1.067 & 0.999 \\
343 & 1.1350 & 1.124 & 0.998 \\
\hline
\end{tabular}

$\mathrm{K}_{\mathrm{Lads}}=$ Langmuir adsorption constant, $\mathrm{m}=\mathrm{a}$ numerical value representing the slope.

Temkin adsorption

Temkin adsorption isotherm, as applied to corrosion studies, takes into account the interaction between adsorbent and adsorbate ions or molecules, and it is based on the assumption that the free energy of adsorption is a function of surface coverage [12]. The equation of Temkin adsorption isotherm is given as:

$$
\theta=2.303 K_{T} \log C
$$

where $\theta$ is the surface coverage, $\mathrm{K}_{\mathrm{T}}$ is the Temkin adsorption constant and $\mathrm{C}$ is the inhibitor concentration. The Temkin plot for the inhibitor adsorption onto the mild steel surface, in a $1 \mathrm{M} \mathrm{HCl}$ solution, at various temperatures, was done by plotting the surface coverage, $\theta$, against Log $C$ (Fig. 8). Temkin parameters are shown in Table 6. 
The $\theta$ Temkin plots versus $\log C_{\text {inh }}$, at various studied temperatures, of the leaves extract solution, are depicted in Fig. 8. The graphic is linear and $\mathrm{K}_{\text {Tads }}$ values increased at higher temperatures, while their correlation coefficient, $\mathrm{R}^{2}$, is in a good range from 0.962 to 0.825 , with the exception of $\mathrm{R}^{2}=0.024$ (Table 6). A similar finding has been reported in literature [23, 24].

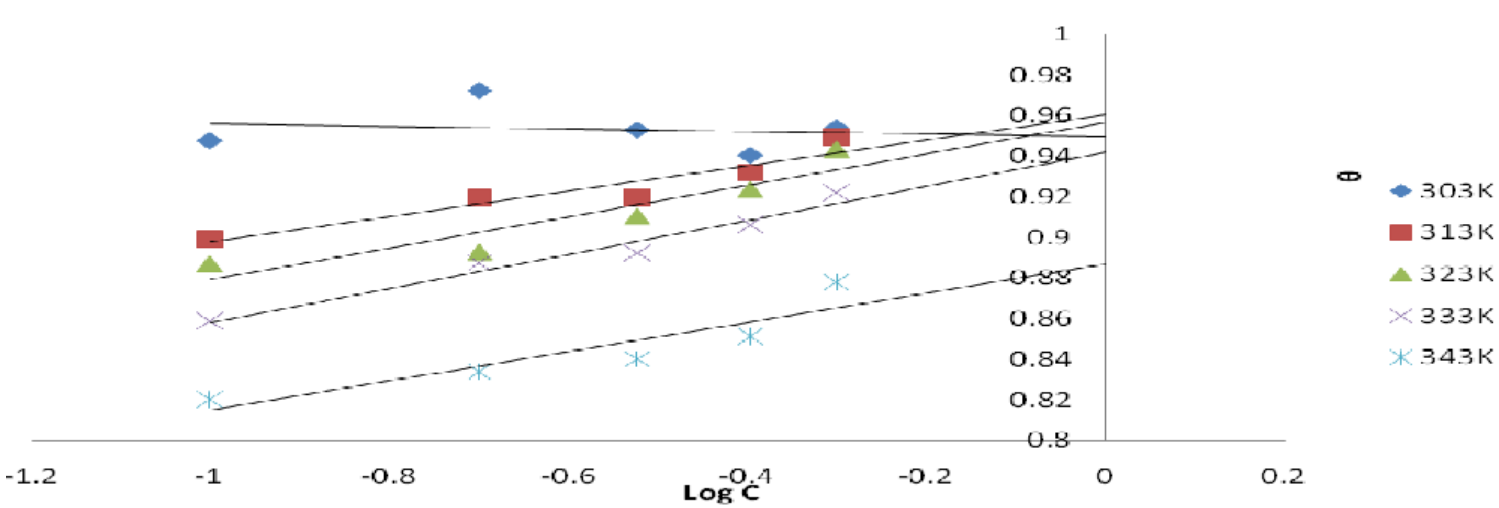

Figure 8. Temkin plot for mild steel in a $1 \mathrm{M} \mathrm{HCl}$ solution with different $P$. polyandra leaves extract concentrations, at various temperatures.

Table 6. Temkin parameters for mild steel in a $1 \mathrm{M} \mathrm{HCl}$ solution with different $P$. polyandra leaves extract concentrations, at various temperatures.

\begin{tabular}{llll}
\hline & \multicolumn{2}{l}{ Leaf extract } & \\
\hline $\begin{array}{l}\text { Temperature } \\
(\mathbf{K})\end{array}$ & $\begin{array}{l}\text { KTads. } \\
(\mathbf{g} / \mathbf{L})\end{array}$ & $\mathbf{m}$ & $\mathbf{R}^{\mathbf{2}}$ \\
\hline 303 & 0.9487 & 0.006 & 0.024 \\
313 & 1.0163 & 0.063 & 0.894 \\
323 & 1.0214 & 0.076 & 0.860 \\
333 & 1.0218 & 0.083 & 0.962 \\
343 & 0.9446 & 0.071 & 0.825 \\
\hline
\end{tabular}

$\mathrm{K}_{\text {Tads }}=$ Temkin adsorption constant, $\mathrm{m}=$ a numerical value representing the slope.

Among the three investigated adsorption isotherms, Langmuir was found to be the best to fit the corrosion adsorption data, by the virtue of its higher correlation coefficient, $\mathrm{R}^{2}$, value.

\section{Thermodynamic studies}

Thermodynamic properties, such as activation energy $\left(E_{a}\right)$, enthalpy $(\Delta H)$ and entropy of activation $(\Delta \mathrm{S})$, show the involved adsorption mechanism. The $\mathrm{E}_{\mathrm{a}}, \Delta \mathrm{H}$ and $\Delta S$ values obtained from the Arrhenius plot of Log $C R$ against $1 / T$ values are given in Tables 7 and 8 . The activation energy $\left(E_{a}\right)$ values decreased as the concentrations increased. The $\mathrm{E}_{\mathrm{a}}$ of an uninhibited solution was found to be 45.79 $\mathrm{kJ} / \mathrm{mol}$. Raising the inhibitor concentration from $0.1 \mathrm{~g} / \mathrm{L}$ to $0.4 \mathrm{~g} / \mathrm{L}$ led to the $\mathrm{E}_{\mathrm{a}}$ value reduction from $45.79 \mathrm{~kJ} / \mathrm{mol}$ to $8.97 \mathrm{~kJ} / \mathrm{mol}$, at a concentration of $0.4 \mathrm{~g} / \mathrm{L}$. The addition of a higher leaves extract (inhibitor) concentration produced a better and thicker protective film layer on the mild steel surface, at a particular temperature. 
Table 7. Activation parameters of mild steel dissolution in uninhibited $1 \mathrm{M} \mathrm{HCl}$ and in the presence of different leaves extracts concentrations.

\begin{tabular}{llllll}
\hline $\begin{array}{c}\mathbf{L E C} \\
\mathbf{( g / L )}\end{array}$ & $\begin{array}{c}\mathbf{E}_{\mathbf{a}} \\
\mathbf{( k j} /\end{array}$ & \multicolumn{1}{c}{$\mathbf{R}^{\mathbf{2}}$} & $\begin{array}{c}\Delta \mathbf{H} \\
\mathbf{( k j} /\end{array}$ & $\begin{array}{c}\Delta \mathbf{S} \\
\mathbf{( j / m o l}\end{array}$ & \multicolumn{1}{c}{$\mathbf{R}^{\mathbf{2}}$} \\
\hline Uninhibited & 45.79 & 0.341 & 70.61 & - & 0.2169 \\
$0.1 \mathrm{~g} / \mathrm{L}$ & 24.92 & 0.9126 & 104.69 & - & 0.9400 \\
$0.2 \mathrm{~g} / \mathrm{L}$ & 24.05 & 0.9565 & 108.59 & -150.8 & 0.9300 \\
$0.3 \mathrm{~g} / \mathrm{L}$ & 23.08 & 0.9481 & 66.83 & - & 0.7813 \\
$0.4 \mathrm{~g} / \mathrm{L}$ & 8.97 & 0.6335 & 57.69 & - & 0.8841 \\
$0.5 \mathrm{~g} / \mathrm{L}$ & 24.96 & 0.8398 & 105.8 & - & 0.9342 \\
\hline
\end{tabular}

LEC $=$ Leaves extract concentration, $E_{a}=$ activation energy, $\Delta \mathrm{H}=$ enthalpy of activation, $\Delta \mathbf{S}=$ entropy of activation.

The trend of increase in the $\mathrm{E}_{\mathrm{a}}$ value, at higher inhibitors concentrations, has been reported on various green plant extracts $[19,25]$.

The $E_{a}$ values were used in this study to know the adsorption mechanism that took place [26]. It was found that the $\mathrm{E}_{\mathrm{a}}$ constant or lower values $(8.97-24.96 \mathrm{KJ} / \mathrm{mol})$ in an inhibited system, compared to those of the blank solution (uninhibited), indicate an inhibition chemisorption process. So, an optimum lowered $E_{a}$ value of the inhibited solution indicates the $P$. polyandra leaves extract inhibition efficiency, which is comparable to the values obtained in literature [5]. Therefore, the adsorption mechanism might be suggested to be chemisorption. The plot of log $\mathrm{C}_{\mathrm{R}}$ against the uninhibited solution temperature inverse produced a scattered graph with a very low correlation coefficient, $R^{2}$ (Fig. 9).

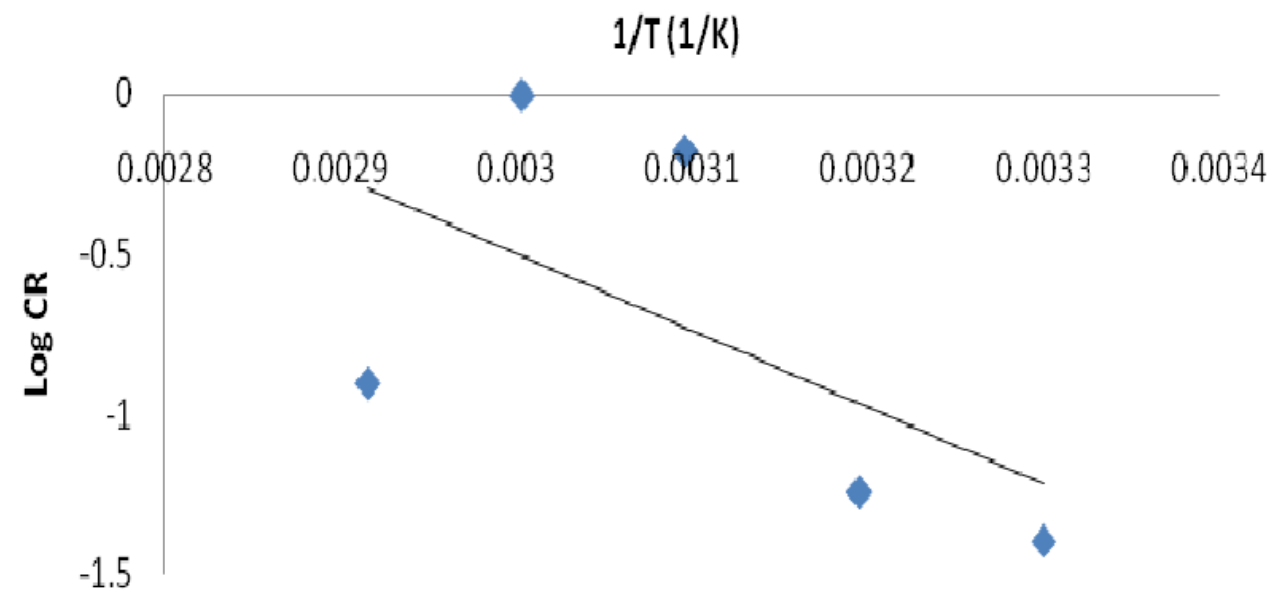

Figure 9. Arrhenius plot for mild steel in an uninhibited $1 \mathrm{M} \mathrm{HCl}$ solution.

Figs. 10a and $\mathrm{b}$ show the Arrhenius plot for mild steel in a $1 \mathrm{M} \mathrm{HCl}$ inhibited solution with different extract concentrations. 


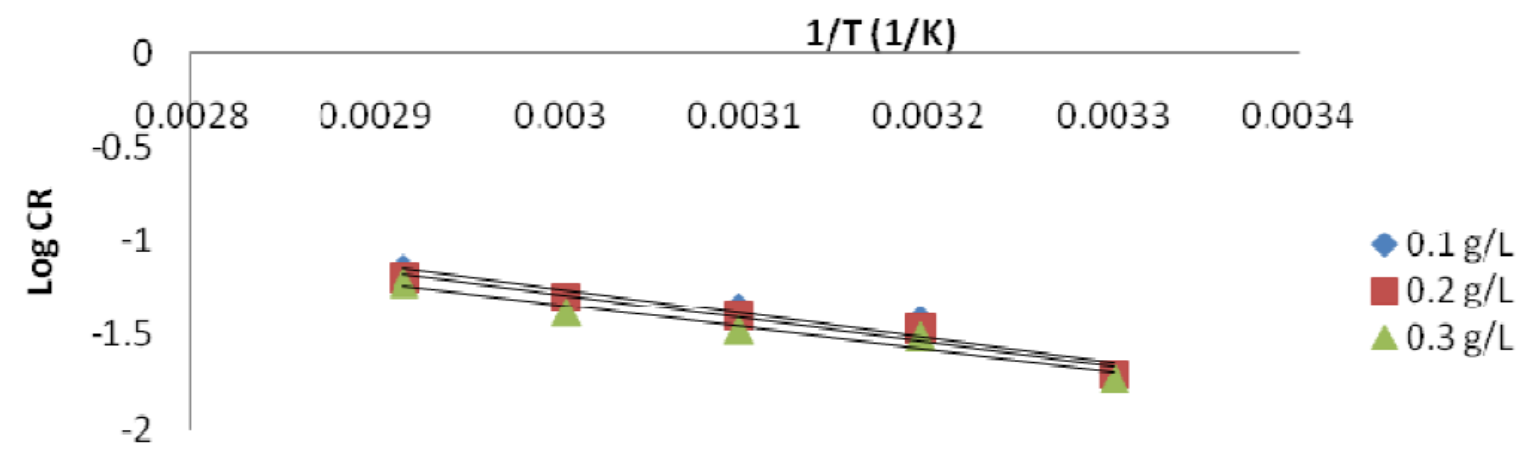

Figure 10a. Arrhenius plot for mild steel in a $1 \mathrm{M} \mathrm{HCl}$ solution containing $0.1,0.2$ and $0.3 \mathrm{~g} / \mathrm{L}$ P. Polyandra leaves extracts concentrations.

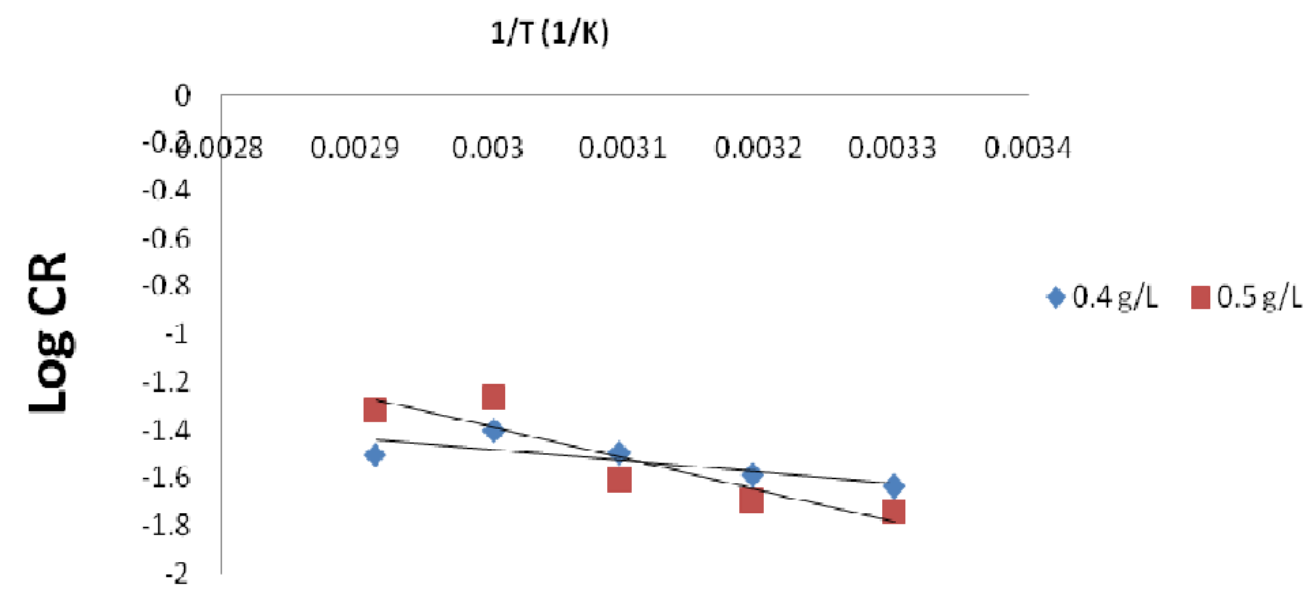

Figure 10b. Arrhenius plot for mild steel in a $1 \mathrm{M} \mathrm{HCl}$ solution containing 0.4 and $0.5 \mathrm{~g} /$ L P. Polyandra leaves extracts concentrations.

\section{Kinetics model}

The corrosion reaction is a heterogeneous reaction which is composed of anodic and cathodic reactions at the same or different rate. It is on this basis that the data kinetic analysis is considered necessary.

For first order kinetics,

$$
r=-d\left(\frac{w_{i}-w_{t}}{d t}\right)=k_{1} w_{t}
$$

where $\mathrm{w}_{i}$ is the initial weight of the mild steel, $\mathrm{w}_{\mathrm{t}}$ is the weight after time, $\mathrm{t}$, and $\mathrm{k}_{1}$ is the first order rate constant, which has a unit of $\mathrm{h}^{-1}$.

Integrated first order is given as:

$$
\operatorname{In}\left(w_{i}-w_{t}\right)=-k_{1} t+\operatorname{In} w_{t}
$$

From the plot of In $\left(\mathrm{w}_{1}-\mathrm{w}_{\mathrm{t}}\right)$ against $\mathrm{t}(\mathrm{h}), \mathrm{k}_{1}$ was estimated as the slope, while intercept as Inw. The rate constant was calculated from its slope, as reported by the previous investigators [27]. The linear variation and slope, $\mathrm{k}_{1}$, confirm a first order reaction kinetics with respect to mild steel corrosion in a $1 \mathrm{M} \mathrm{HCl}$ solution, in the inhibitor presence. Figs. 11 and 12 show that the plots slopes have negative values and good correlation coefficients $\left(\mathrm{R}^{2}\right)$ with obtained linear plots, which proofs that the reaction followed first order kinetic model, in line with Eddy et al. 
[28] findings that investigated the corrosion inhibition efficiency of ethanol extract of mango peel waste on mild steel.

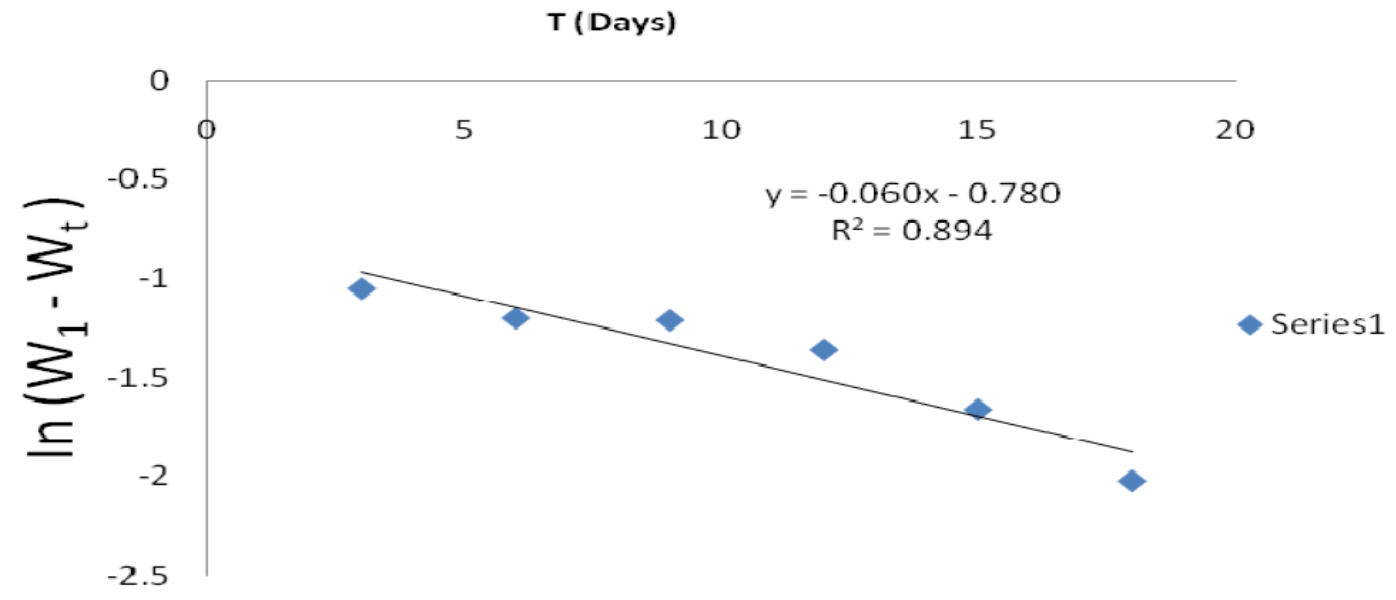

Figure 11. First order kinetic plot of mild steel weight loss against immersion time, in an uninhibited $1 \mathrm{M} \mathrm{HCl}$ solution.

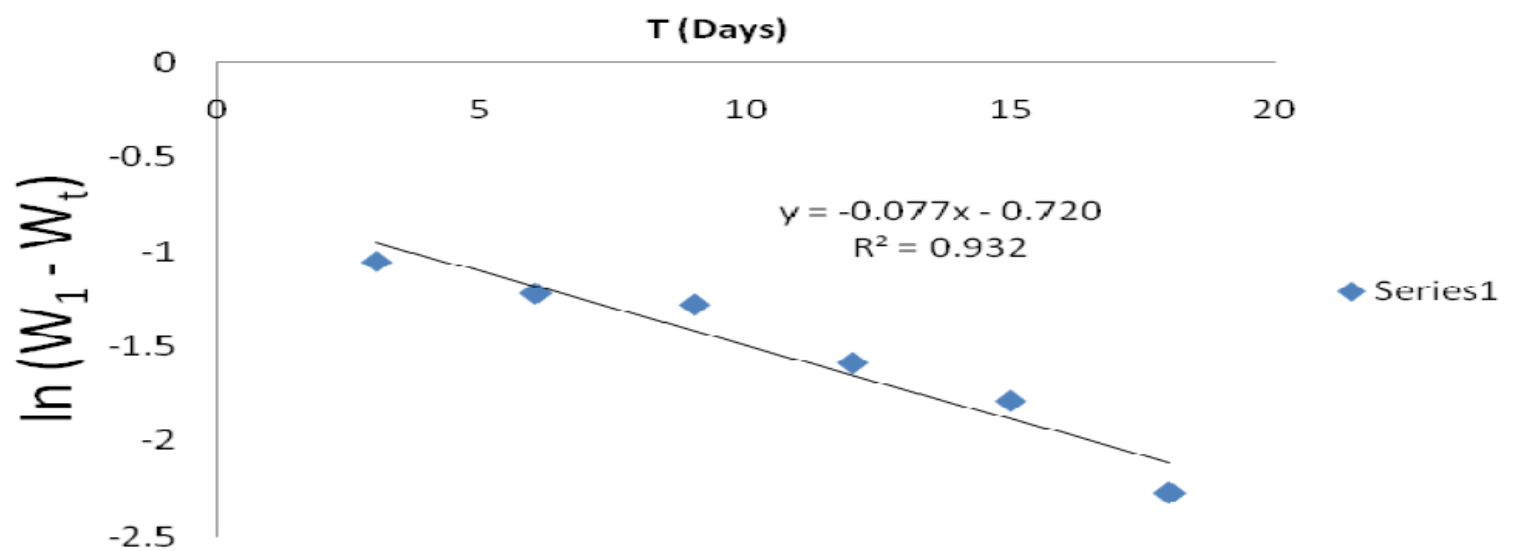

Figure 12. First order kinetic plot of mild steel weight loss against immersion time, in various $P$. polyandra leaves extracts concentrations, in a $1 \mathrm{M} \mathrm{HCl}$ solution.

\section{Electrochemical studies}

The electrochemical method of corrosion studies is the most reliable to give information about the mechanism of a corrosion process, and it is not a time consuming method, unlike the gravimetric method. Table 8 shows the parameters obtained from the electrochemical studies of $P$. polyandra leaves extract as corrosion inhibitor for mild steel in a $1 \mathrm{M} \mathrm{HCl}$ solution [29].

Table 8. Electrochemical parameters obtained from the $P$. polyandra leaves extracts electrochemical studies.

\begin{tabular}{llllllll}
\hline $\begin{array}{l}\text { Inhibitor } \\
\text { concentration } \\
(\mathbf{g} / \mathbf{L})\end{array}$ & $\begin{array}{l}\text { Ecorr } \\
(\mathbf{m v})\end{array}$ & $\begin{array}{l}\mathbf{I}_{\text {corr }} \\
\left(\boldsymbol{\mu A} / \mathbf{c m}^{\mathbf{2}}\right)\end{array}$ & $\boldsymbol{\beta a}$ & $\boldsymbol{\beta c}$ & $\begin{array}{l}\text { C.R } \\
(\mathbf{m m p y})\end{array}$ & $\begin{array}{l}\text { I E } \\
(\mathbf{\%})\end{array}$ & $\begin{array}{l}\text { Chi } \\
\text { square }\end{array}$ \\
\hline Uninhibited & -479.23 & -1.518 & 153.28 & 102.04 & 17.63 & $\mathrm{NA}$ & 52.87 \\
$0.1 \mathrm{~g} / \mathrm{L}$ & -627.11 & -191.90 & 54.89 & 756.44 & 2.23 & 79.90 & 61.13 \\
$0.3 \mathrm{~g} / \mathrm{L}$ & -589.45 & -13.13 & 328.72 & 1.565 & 0.15 & 88.49 & 195.72 \\
$0.5 \mathrm{~g} / \mathrm{L}$ & -558 & -1.76 & 92.737 & 156.29 & 0.02 & 95.34 & 195.72 \\
\hline
\end{tabular}


Electrochemical studies of mild steel corrosion inhibition using $P$. polyandra leaves extract, by Tafel electrochemical analysis, gave various corrosion parameters values for different inhibitor concentrations. Table 8 reveals that the leaves extract inhibitor altered the anodic beta $\left(\beta_{\mathrm{a}}\right)$ value $(153.28)$ and the cathodic beta $(\beta \mathrm{c})$ value (102.04) obtained from the uninhibited solution. Thus, the inhibitor acted as a mixed inhibitor [30].

From Table 8, it could be seen that the corrosion rate decreased significantly, from 17.63 mmpy of the uninhibited system, to $2.23 \mathrm{mmpy}$ and $0.02 \mathrm{mmpy}$, at a concentration of $0.1 \mathrm{~g} / \mathrm{L}$ and $0.5 \mathrm{~g} / \mathrm{L}$, respectively, of the leaves extracts. Fig. 13 represents the Tafel plot of the isolated leaves extract as corrosion inhibitor of mild steel in a $1 \mathrm{M} \mathrm{HCl}$ solution.

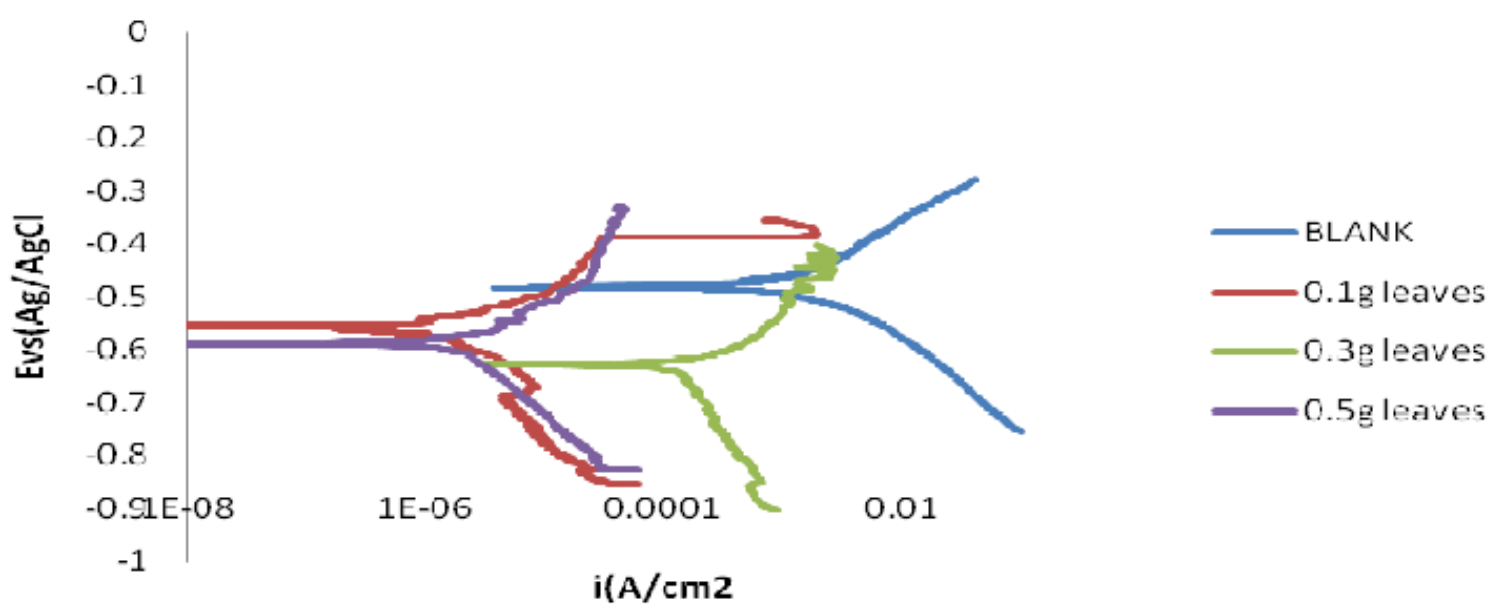

Figure 13. Tafel plot of isolated leaves extract as a corrosion inhibitor of mild steel in a 1 $\mathrm{M} \mathrm{HCl}$ solution.

Scanning Electron Microscopy analysis (SEM)

Scanning electron microscopy analytical technique revealed the visual physical morphological changes on the surface of mild steel that was separately immersed in uninhibited $1 \mathrm{M} \mathrm{HCl}$ solutions and in inhibited $\mathrm{HCl}$ solutions with different $P$. polyandra leaves extract concentrations. SEM images for mild steel immersed in an uninhibited $1 \mathrm{M} \mathrm{HCl}$ solution and in a solution with $0.5 \mathrm{~g} / \mathrm{L}$ of leaves extracts, for $48 \mathrm{~h}$, at $303 \mathrm{~K}$, are shown in Figs. 14 and 15. The images revealed that, in the inhibitor absence, cracks resulted from a corrosion attack on the mild steel surface, while the cracks and corroded areas were reduced in the SEM images of the mild steel inhibited with various leaves extract concentrations. This is due to the formation of protective layers by the molecules inhibiting the mild steel corrosion [5].

The image in Fig. 14 shows many cracks due to the corrosion attack on the mild steel surface [10]. The image in Fig. 15 reveals no obviously crack occurrences. This is due to the presence of the leaves extract inhibitor that was adsorbed onto the mild steel surface, thus protecting it from corrosion attack $[5,10]$. 


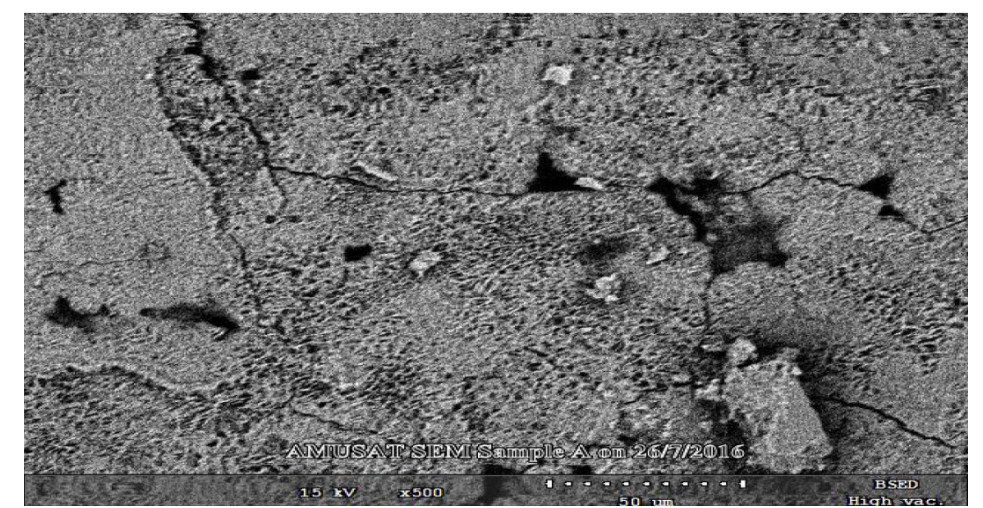

Figure 14. Mild steel SEM micrograph in an uninhibited $1 \mathrm{M} \mathrm{HCl}$ solution, after 48 hours of immersion, at a magnification of 500x.

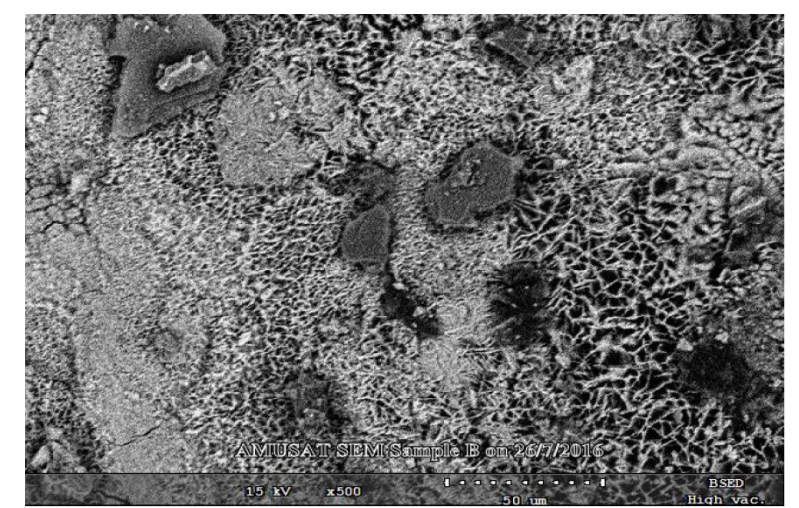

Figure 15. Mild steel SEM micrograph in an inhibited $1 \mathrm{M} \mathrm{HCl}$ solution, after 48 hours of immersion, at a magnification of 500X.

\section{Conclusion}

In conclusion, ethanolic leaves extract of $P$. polyandra exhibited good inhibiting characteristics against mild steel corrosion in a $1 \mathrm{M} \mathrm{HCl}$ solution. This might be due to the carbonyl and hydroxyl groups presence in the leaves extract, which served as an adsorption site onto the mild steel surface. SEM analysis also confirmed the mild steel corrosion inhibition, in a $1 \mathrm{M} \mathrm{HCl}$ solution, by the $P$. polyandra leaves extract, showing its high inhibition potential. Both gravimetric and electrochemical methods showed that the leaves extract solution inhibition efficiency decreased with higher temperatures and increased with longer mild steel immersion periods in it. Langmuir adsorption isotherm best described the leaves extract adsorption onto the mild steel surface, which has followed an endothermic process. The first order kinetics also favored the $P$. polyandra leaves extract adsorption onto the mild steel surface.

\section{References}

1. Lusk D, Gupta M, Boinapally $\mathrm{K}$, et al. Armoured against corrosion. Hydrocarbon Eng. 2008;3(11):115-118.

2. Roberge PR. Handbook of Corrosion Engineering. New York: McGraw-Hill; 2000. 
3. Pandian B, Raja M, Gopalakrishnan S. Natural products as corrosion inhibitor for metals in corrosive media - A review. Mat Lett. 2008;62(1):113-116. https://doi.org/10.1016/j.matlet.2007.04.079.

4. El Bribri A, Tabyaoui M, Tabyaoui B, et al. The use of Euphorbia falcata extract as eco-friendly corrosion inhibitor of carbon steel in hydrochloric acid solution. Mats Chem and Phys. 2013;141(1):240-247. https://doi.org/10.1016/j.matchemphys.2013.05.006.

5. Nwosu FO, Muzakir MM. Thermodynamics and adsorption studies of corrosion inhibition of mild steel using lignin from siam weed (Chromolena odorata) in acid medium. J Mat Environ Sci. 2016;(5):1663-1673.

6. Znini M, Majidi L, Bouyanzer A, et al. Essential oil of salvia aucheri mesatlantica as a green inhibitor for the corrosion of steel in $0.5 \mathrm{M} \mathrm{H}_{2} \mathrm{SO}_{4}$. Arab J Chem. 2012;5(4):467-474. https://doi.org/10.1016/j.arabjc.2010/09.017.

7. El-Etre AY. Inhibition of aluminum corrosion using Opuntia extract. Corros Sci. 2003;45(11):2485-2495. https://doi.org/10.1016/S0010-938X(03)000660 .

8. Nnanna LA, Anozie IU, Akoma CS, et al. Corrosion control of aluminium alloy in alkaline solution using some leave extracts. Amer J Mat Sci. 2011;1(2):76-80. https://doi.org/10.5923/j.materials.20110102.12.

9. Kavitha V, Gunavathy N. Evaluation of Daucug carota aerial extract as corrosion inhibition for mild steel. Int J Res in Advent Techn. 2014;2(7):146154.

10. Nnanna LA, Owate IO, Oguzie EE. Inhibition of Mild Steel Corrosion in $\mathrm{HCl}$ Solution by Pentaclethra macrophylla Bentham extract. Int $\mathrm{J}$ Mat Eng. 2014;4(5):171-179. https://doi.org/10.5923/j.ijme.20140405.02

11. El-Etre AY. Natural onion juice as inhibitor for zinc corrosion. Bull Electrochem. 2006; 22(2):75-80.

12. Deepa $\mathrm{R}$, Selvaraj S. Inhibitive and adsorption properties of punica granatum extract on brass in acid media. J Phytol. 2010;2(11):58-64.

13. Lahhit N, Bouyanzer A, Desjobert M. Fennel (Foeniculum vulgare) essential oil as green corrosion inhibitor of carbon steel in hydrochloric acid solution. Port Electrochim Acta. 2011;29(2):127-138. https://doi.org/10.4152/pea/201102127.

14. Sangeetha M, Rajendran S, Sathiyabania J, et al. Inhibition of corrosion of aluminium and its alloy by extracts of green inhibitors. Port Electrochim Acta. 2013;31(1):41-52. https://doi.org/10.4152/pea201301041.

15. Umoru LE, Fawehinmi IA, Fasasi AY. Investigation of the Inhibitive Influence of Theobroma cacao and Cola acuminate Leaves Extracts on the corrosion of a Mild Steel in Sea Water. J Appl Sci Res. 2006;2(4):200-204. 2006.

16. Awe FE, Idris SO, Abdulwahab M, et al. Inhibitive and adsorptive effect of Parinari polyandra on mild steel corrosion in aqueous sulphuric acid. J Pure and Appl Chem. 2015;9(6):125-134. 
17. Hamdy A, El-gendy NS. Thermodynamic, adsorption and electrochemical studies for corrosion inhibition of carbon steel by henna extract in acid medium. Egyp J Petro. 2013:1- 9. https://doi.org/10.1016/j.ejpe/2012/06/002.

18. Eddy NO. Adsorption and inhibitive properties of ethanol extract of Colocasia esculenta on the inhibition of the corrosion of mild steel in $\mathrm{H}_{2} \mathrm{SO}_{4}$. Int $\mathrm{J}$ Phys Sci. 2009;27(1):4(4):165-171.

19. Singh A, Singh KL, Quraishi MA. Effect of fruit extracts of some environmentally benign green corrosion inhibitors on corrosion of mild steel in hydrochloric acid solution. J Mat Environ Sci. 2010;1(3):162-174.

20. Obot IB, Obi-Egbedi NO. An interesting and efficient green corrosion inhibitor for aluminium from extracts of Chlomolaena odorata L. in acidic solution. J Appl Electrochem. 2009; 40(11):1977-1983. https://doi.org/10.1007/s10800-010-0175-x

21. Akpan IA, Offiong NO. Inhibition of mild steel corrosion in Hydrochloric acid solution by ciprofloxacin Drug. Int J Agric Sci. 2013;13:583-589. https://doi.org/10.1155/2013/301789.

22. James AO, Akaranta O. The inhibition of carbon of Zinc in $2 \mathrm{M}$ hydrochloric Acid solution with acetone extract of red onion skin. Afr J Pure and Appl Chem. 2009;3(11):212-217.

23. Nnanna LA, Obasi VU, Nwadiuko OC, et al. Inhibition by Newbouidia leavis leaf extract of the corrosion of aluminum in $\mathrm{HCl}$ and $\mathrm{H}_{2} \mathrm{SO}_{4}$ solution. Archi of Appl Sci Res. 2012;4(1):207-217.

24. Ituen BI, Edidiong A, Essien B, et al. Experimental and theoretical study of corrosion inhibition effect of Cucumeropsis mannii N. seed oil metallic soap of zinc on mild steel surface in sulphuric acid. J Adv Appl Sci Res. 2014;5(3):26-53.

25. Ajayi OM, Odusote JK, Yahya RA. Inhibition of mild steel corrosion using Jatropha curcas leaf extract. J Electrochem Sci and Eng. 2014;4(2):67-74. https://doi.org/10.5599/jese.2014.0047.

26. Zarrouk A, Hammouti B, Zarrok H, et al. Temperature effect, activation energies and thermodynamic adsorption studies of 1-Cysteine Methyl Ester Hydrochloride as copper corrosion inhibitor in nitric acid $2 \mathrm{M}$. Int $\mathrm{J}$ Electrochem Sci. 2011;6(12):6261-6274.

27. James AO, Oforka NC, Abiola OK. Inhibition of Aluminium (3SR) corrosion in hydrochloric acid by pyridoxol hydrochloride. Eclética Química, São Paulo. 2007; 32(3):31-38. https://doi.org/10.1590/S0100-46702007000300005

28. Eddy NO, Odomelam SA, Odiongenyi AO. Ethanol extracts of musa speices peels asa green corrosion inhibitors for mild steel: kinetics, adsorption and thermodynamics considerations. Electronic J Environ Agric and Food Chem. 2009;8(4): 243-255.

29. Eduok UM, Umoren SA, Udoh AP. Synergistic inhibition effects between leaves and stem extracts of Sida acuta and iodide ion for mild steel corrosion in $1 \quad \mathrm{M} \quad \mathrm{H}_{2} \mathrm{SO}_{4}$ solutions. Arab $\mathrm{J}$ Chem. 2012;5:325-337. https://doi.org/10.1016/j.arabjc.2010.09.007.

30. Kumar KPV, Pillai MSN, Thusnavis R. Seed extract of Psidium guajava as ecofriendly corrosion inhibitor for carbon steel in hydrochloric acid medium. J 
F.O. Nwosu \& S.O. Amusat / Portugaliae Electrochimica Acta 39 (2021) 431-449

Mat Sci Techno. 2011;27:1143-1149. https://doi.org/10.1016/S10050302(12)60010-3. 